\title{
Alteration in Downstream Hypoxia Gene Signaling in Neonatal Glutathione Peroxidase Overexpressing Mouse Brain after Hypoxia-Ischemia
}

\author{
R. Ann Sheldon ${ }^{a, c}$ Raha Sadjadia, c Matthew Lam ${ }^{a, c}$ Russell Fitzgerald ${ }^{a, c}$ \\ Donna M. Ferriero ${ }^{\mathrm{a}-\mathrm{c}}$ \\ Departments of a Pediatrics, ${ }^{\mathrm{b}}$ Neurology and ${ }^{\mathrm{c}}$ Newborn Brain Institute, UCSF Benioff Children's Hospital, University of \\ California San Francisco, San Francisco, Calif., USA
}

\section{Key Words}

Glutathione peroxidase · Hydrogen peroxide .

Hypoxia-ischemia - Neonatal brain injury .

Hypoxia-inducible factor $\cdot$ ERK

\begin{abstract}
We have previously shown that glutathione peroxidase (GPx) overexpressing mice (hGPx-tg) have reduced brain injury after neonatal hypoxia-ischemia (HI) as a consequence of reduced hydrogen peroxide accumulation. However, this protection is reversed with hypoxia preconditioning, raising the question of the roles of the genes regulated by hypoxiainducible factor-1a (HIF-1a) and their transcription products, such as erythropoietin (EPO), in both the initial protection and subsequent reversal of protection. hGPx-tg and their wild-type (WT) littermates underwent the Vannucci procedure of $\mathrm{HI}$ brain injury at postnatal day 9 - left carotid artery ligation followed by exposure to $10 \%$ oxygen for $50 \mathrm{~min}$. Brain cortices and hippocampi were subsequently collected $0.5,4$ and $24 \mathrm{~h}$ later for the determination of protein expression by Western blot for GPx, HIF-1a, HIF-2a, EPO, EPO receptor, ERK1/2, phospho-ERK1/2, spectrin 145/150 (as a marker of calpain-specific necrotic cell death), and spectrin
\end{abstract}

120 (as a marker of apoptotic cell death mediated via caspase-3). As expected, the GPx overexpressing mouse cortex had approximately 3 times the GPx expression as WT naïve. Also, GPx expression remained higher in the GPx overexpressing brain than WT at all time points after $\mathrm{HI}(0.5,4,24 \mathrm{~h})$. HIF-1a was not significantly changed in hGPx-tg as a consequence of $\mathrm{HI}$ but decreased in the WT cortex $4 \mathrm{~h}$ after HI. HIF2 a decreased in the WT hippocampus after HI. EPO was higher in the GPx overexpressing cortex and hippocampus 30 min after $\mathrm{HI}$ compared to WT, but the EPO receptor was unchanged by $\mathrm{HI}$. ERK $1 / 2$ phosphorylation increased in the hippocampus at $4 \mathrm{~h}$ after $\mathrm{HI}$ and in the cortex at $24 \mathrm{~h}$ after $\mathrm{HI}$ in both WT and hGPx-tg. Spectrin 145/150 was increased in the WT cortex at 4 and $24 \mathrm{~h}$ after $\mathrm{HI}$, and spectrin $120 \mathrm{in}$ creased $24 \mathrm{~h}$ after $\mathrm{HI}$, perhaps reflecting greater injury in the WT brain, especially at $24 \mathrm{~h}$ when brain injury is more evident. The effect of GPx overexpression does not appear to upregulate the HIF pathway, yet EPO was upregulated, perhaps via ERK. This might explain, in part, why cell death takes a necrotic or apoptotic path. This may also be an explanation for why the GPx overexpressing brain cannot be preconditioned. This information may prove valuable in the development of therapies for neonatal HI brain injury.

(c) 2015 S. Karger AG, Basel

\section{KARGER 125}

(c) 2015 S. Karger AG, Base

0378-5866/15/0375-0398\$39.50/0

E-Mail karger@karger.com

www.karger.com/dne
R. Ann Sheldon

Department of Pediatrics, University of California San Francisco 675 Nelson Rising Lane, Box 0663

San Francisco, CA 94158 (USA)

E-Mail Ann.sheldon@ucsf.edu 


\section{Introduction}

The developing brain is highly susceptible to oxidative stress, more so than the adult brain [1]. As a consequence of immature antioxidative mechanisms, for example, the developing mouse brain accumulates more $\mathrm{H}_{2} \mathrm{O}_{2}$ after hypoxia-ischemia (HI) than the adult [2]. This disparity is presumably due to lower levels of glutathione peroxidase $(\mathrm{GPx})$ in the immature brain [3] Under normal physiological circumstances, $\mathrm{H}_{2} \mathrm{O}_{2}$ is produced as a result of the conversion of superoxide by superoxide dismutase. GPx then reduces $\mathrm{H}_{2} \mathrm{O}_{2}$ by converting it to oxygen and water. After $\mathrm{HI}$, endogenous levels of GPx are inadequate for the excess $\mathrm{H}_{2} \mathrm{O}_{2}$ generated in the neonatal brain, but mice that overexpress GPx (hGPx-tg) have less brain injury 5 days after HI and increased GPx activity $24 \mathrm{~h}$ after HI than wild-type (WT) littermates [4]. There is also protection against exogenous $\mathrm{H}_{2} \mathrm{O}_{2}$ in primary neuronal cultures in hGPx-tg. Specific depletion of GSH with buthionine sulfoximine in these cultures increased cell death, abolishing the protection afforded by the increased GPx activity and therefore implicating the availability of reducing equivalents in neuroprotection [5]. Further support for the importance of GPx in ameliorating injury comes from work with GPx-deficient mice that have shown increased injury after ischemia/reperfusion in the adult brain [6] We have also seen increased injury in these GPx-deficient mice when subjected to $\mathrm{HI}$ at postnatal day 7 (P7) [unpubl. data].

This protective effect of increased GPx against oxidative stress is lost, however, when the hGPx-tg mice are exposed to hypoxia preconditioning prior to $\mathrm{HI}$ [7]. Hypoxia preconditioning has been shown to reduce subsequent injury [8] and, indeed, the WT littermates in this study had reduced injury. Accordingly, hypoxia-inducible factor-1 $\alpha$ (HIF-1 $\alpha$ ) and the products of its target genes were subsequently shown to be key to hypoxia preconditioning protection [9-11]. Perhaps the activation of HIF-1 $\alpha$ and its target genes is necessary for protection in neonatal $\mathrm{HI}$ both in the setting of $\mathrm{HI}$ and preconditioning. In fact, we have shown that the elimination of HIF-1 results in loss of protection and loss of preconditioning $[12,13]$.

One of the HIF gene products, erythropoietin (EPO), has frequently been suggested as a protective agent when administered after HI [14-16]. A possible mechanism for the protective effect of EPO treatment is through increased GPx activity. In support of this idea, Kumral et al. [17] found increased GPx activity after EPO treatment of neonatal rats subjected to $\mathrm{HI}$, suggesting that the neuroprotective effects of EPO are due, at least in part, to modulation of GPx. It is not known whether endogenous EPO has a similar effect on GPx levels $[18,19]$.

Previously, we showed HIF-1 1 to be elevated equally in both the WT and hGPx-tg cortex immediately after hypoxia alone. However, ERK1/2 phosphorylation was elevated only in the WT (at $30 \mathrm{~min}$ after hypoxia) [20]. After HI in neonatal rats, both HIF and p-ERK are upregulated at $4-8 \mathrm{~h}$ after the injury and the induction of HIF is blocked by a specific inhibitor of ERK1/2 [21].

The present study explores the role of hypoxia gene signaling in the setting of GPx overexpression in the neonatal brain through characterization of the expression of GPx, HIF-1 $\alpha$, HIF-2 $\alpha$ (which is thought to be astrocyte specific [22]), the transcription factor EPO, the EPO receptor (EPOr), ERK1/2, phospho-ERK1/2, and the cell death markers spectrin 145/150 (for evidence of calpainspecific necrosis) and spectrin 120 (for evidence of caspase-3 based apoptosis).

\section{Materials and Methods}

Mice

hGPx1-tg mice were bred and maintained at the UCSF laboratory animal research center. Experiments were approved by the Institutional Animal Care and Use Committee at UCSF, in accordance with NIH guidelines for the Care and Use of Laboratory Animals. Male mice heterozygous for hGPxl were bred with female WT CD1 mice and genotype of the resulting litters was determined by standard methods, as previously described [4, 23]. The mice then underwent the Vannucci procedure of $\mathrm{HI}$ at P9 [24-26]. At $30 \mathrm{~min}, 4 \mathrm{~h}$ or $24 \mathrm{~h}$ after hypoxia, the mice were killed by rapid decapitation, brains removed, and ipsi- and contralateral hippocampi and cortices dissected and flash frozen for Western blot. In addition, naïve GPx-tg and WT mice were deeply anesthetized with Euthasol and perfused intracardially with $4 \%$ paraformaldehyde for immunohistochemistry.

Hypoxia-Ischemia

Under isoflurane anesthesia, the left common carotid artery of each mouse was isolated and permanently ligated. When sufficiently recovered from the anesthesia to walk, the pups were returned to the dam for $1 \mathrm{~h}$. They were then placed in chambers maintained at $36.5^{\circ} \mathrm{C}$ and exposed to $10 \%$ oxygen for $50 \mathrm{~min}$.

Western Blots for Protein Expression

Nuclear and cytoplasmic fractions were prepared from the cortices ( $\mathrm{n}=8$ for all groups) and hippocampi $(\mathrm{n}=10$; however, 2 were combined into 1 sample at homogenization due to the small size of tissue, thus presenting as $\mathrm{n}=5$ for all groups) using the nuclear and cytoplasmic extraction reagents (NE-PER; Pierce Biotechnol- 
ogy, Rockford, Ill., USA), according to the manufacturers protocol. Protein concentrations were measured by BCA assay (Pierce). $20 \mu \mathrm{g}$ of nuclear or $40 \mu \mathrm{g}$ of cytoplasmic protein were loaded onto 4-12\% polyacrylamide gels (Invitrogen, Carlsbad, Calif., USA) for electrophoresis. Proteins were transferred to PVDF membranes (Bio-Rad, Hercules, Calif., USA), and membranes were blocked in $5 \%$ nonfat dry milk for $1 \mathrm{~h}$ at room temperature and incubated in the following antibodies overnight at $4^{\circ} \mathrm{C}$ : GPx (1:1,000; Epitomics, Burlingame, Calif., USA), HIF-1a (1:2,000; Novus Biologicals, Littleton, Co., USA), HIF-2a (1:200; Novus), EPO (1:500; Abcam, Cambridge, Mass., USA), EPOr (1:1,000; Abcam), ERK1/2 (1:4,000; EMD Millipore, Billerica, Mass., USA), phospho-ERK1/2 (1:1,000; Cell Signaling, Danvers Mass., USA), and spectrin (1:4,000; EMD Millipore). $\beta$-Actin (1:2,000; Santa Cruz Biotechnology, Santa Cruz, Calif., USA) was used as a loading control.

\section{Immunohistochemistry for GPX}

Naïve paraformaldehyde-fixed brains of hGPx-tg and WT P9 mice were cut on a vibratome 50 um thick. Sections were incubated in rabbit anti-GPx primary antibody (1:200; Abcam) overnight at $4^{\circ} \mathrm{C}$ and goat anti-rabbit IgG secondary antibody (1:200; Santa Cruz Biotechnology) for $2 \mathrm{~h}$ at room temperature, and diaminobenzidine was used as the chromophore. Mounted sections were counterstained with cresyl violet.

\section{Statistical Analysis}

Optical densities (OD) normalized to $\beta$-actin were analyzed with the unpaired t test. Data are expressed as mean \pm SEM normalized to WT naïve. Statistical analyses were performed with GraphPad Prism 6.0 (San Diego, Calif., USA). p $<0.05$ was considered statistically significant.

\section{Results}

GPx Overexpression Is Demonstrated by Western Blot and Is Visible by Immunohistochemistry

The naïve GPx-tg mouse cortex had several-fold higher GPx protein expression compared to WT naïve ( $\mathrm{p}<$ 0.001 ; fig. 1a), and this difference between GPx-tg and WT was maintained at all time points after $\mathrm{HI}(30 \mathrm{~min}$, $\mathrm{p}<0.002 ; 4 \mathrm{~h}, \mathrm{p}<0.0001 ; 24 \mathrm{~h}, \mathrm{p}<0.0001)$. Results were similar for the hippocampus. Naïve GPX-tg hippocampus compared to WT naïve ( $\mathrm{p}<0.05$; fig. $1 \mathrm{~b}$ ), GPx-tg and WT after HI (30 min and 4 h, both p $<0.05 ; 24 \mathrm{~h}, \mathrm{p}<$ $0.03)$.

In addition, immunohistochemistry demonstrated abundant GPx-positive cells in the naïve hGPx-tg cortex and hippocampus (fig. 1c, d) compared to the WT cortex and hippocampus (fig. 1e, f).

\section{HIF-1 $\alpha$ Protein Expression}

HIF-1 a expression was not different between GPx-tg and WT, whether naïve or after HI in either the cortex or hippocampus (fig. 2a, b). However, there was a de- crease in HIF-1a protein expression in the WT cortex $4 \mathrm{~h}$ after HI compared to the WT naïve cortex ( $\mathrm{p}<0.04$; fig. 2a).

\section{HIF-2 $\alpha$ Protein Expression}

HIF- $2 \alpha$ was also not different between GPx-tg and WT, whether naïve or after $\mathrm{HI}$ in the cortex or hippocampus (fig. 2c, d). However, there was a decrease in HIF-2 $\alpha$ in the hippocampus after $\mathrm{HI}$ compared to WT naïve at $30 \mathrm{~min}$ $(\mathrm{p}<0.006), 4 \mathrm{~h}(\mathrm{p}<0.04)$ and $24 \mathrm{~h}(\mathrm{p}<0.03$; fig. $2 \mathrm{~d})$.

\section{EPO and EPOr Protein Expression}

EPO expression was higher in the GPx-tg cortex 30 min after HI compared to the WT cortex $(\mathrm{p}<0.008$; fig. 3a) as well as the hippocampus ( $<<0.05$; fig. $3 b$ ).

EPOr, however, did not demonstrate any differences between hGPx-tg and WT in the cortex or hippocampus for the naïve or any treatment group (fig. $3 c, d$ ).

\section{ERK1/2 Expression and ERK1/2 Phosphorylation}

ERK1/2 phosphorylation was observed in both the WT and hGPx-tg cortex $24 \mathrm{~h}$ after HI $(\mathrm{p}<0.03$ and $\mathrm{p}<$ 0.05 , respectively; fig. $4 \mathrm{a}$ ). In the hippocampus, ERK1/2 phosphorylation occurred earlier, at $4 \mathrm{~h}$, in both WT and hGPx-tg ( $\mathrm{p}=0.05$ and $\mathrm{p}<0.03$, respectively; fig. $4 \mathrm{~b})$.

\section{Spectrin Expression}

Spectrin 145/150 protein expression was not different between the GPx-tg and WT cortex for any treatment group. However, spectrin 145/150 was increased in the WT cortex at 4 and $24 \mathrm{~h}$ after HI compared to WT naïve (both $\mathrm{p}<0.05$; fig. $5 \mathrm{a}$ ). Spectrin $145 / 150$ protein expression was not different between the GPx-tg and WT hippocampus for any treatment group (fig. 5b). However, spectrin 120 was increased in the WT cortex compared to hGPx-tg ( $24 \mathrm{~h}$ after HI; $\mathrm{p}=0.05)$ and WT naïve ( $\mathrm{p}=0.05$; fig. 5c). Also, spectrin 120 was increased in the WT hippocampus compared to hGPx-tg ( $4 \mathrm{~h}$ after HI; $\mathrm{p}=0.03$ ) and WT naïve $(\mathrm{p}=0.05$; fig. $5 \mathrm{~d})$.

\section{Discussion}

In this study, the overexpression of GPx did not alter the expression of HIF-1 $\alpha$ after neonatal HI. In the WT cortex, HIF-1 1 declined at $4 \mathrm{~h}$ relative to naïve. Despite the lack of HIF accumulation, EPO was upregulated in the cortex and hippocampus of the GPX overexpressing brain relative to WT early after HI (30 min). This may be explained, at least in part, by the increased ERK 

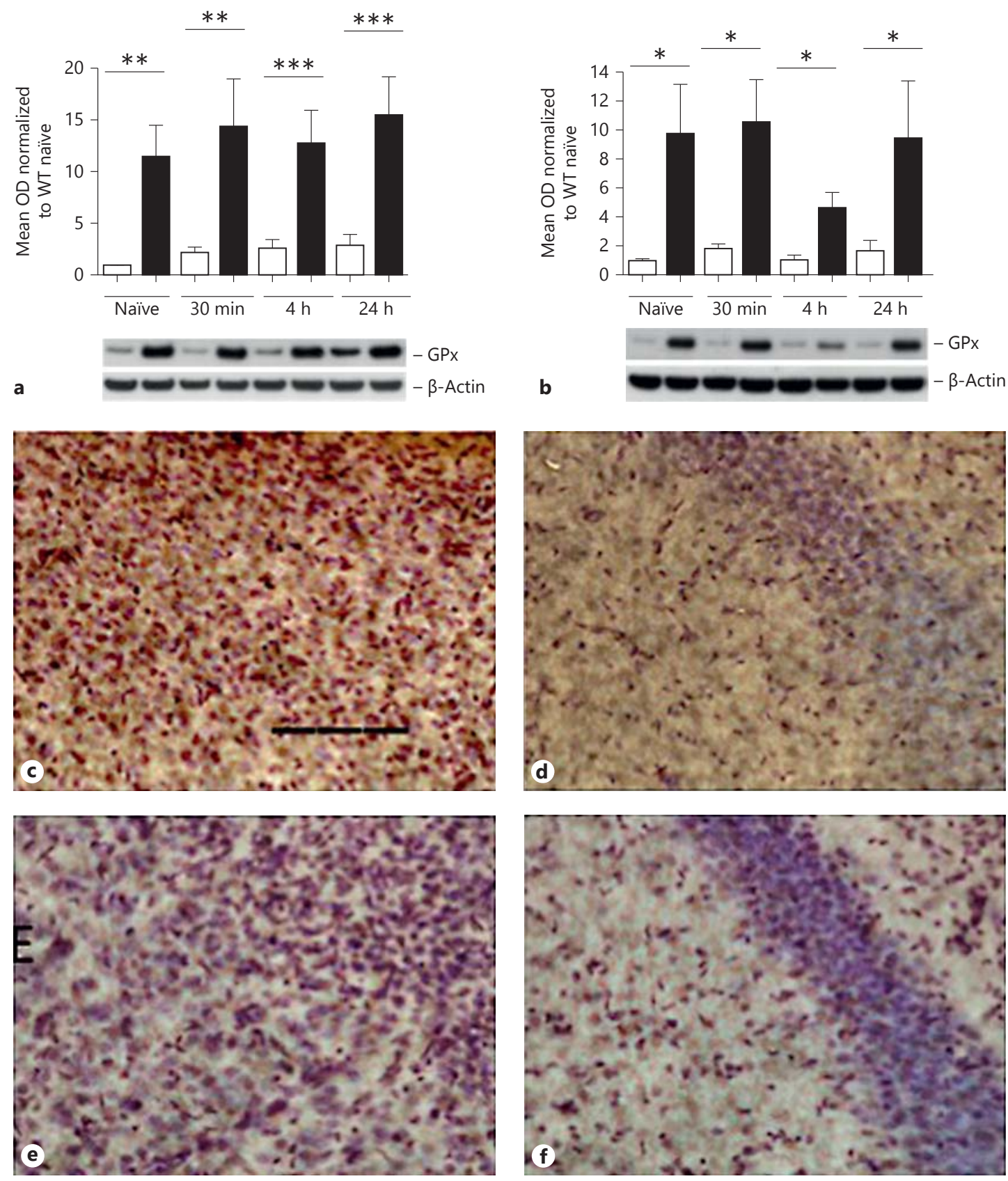

Fig. 1. GPx protein expression is several-fold higher in the hGPxtg mouse cortex and hippocampus compared to the WT cortex and hippocampus. a hGPx cortex compared to WT: naïve (** $\mathrm{p}<$ $0.001), 30$ min after HI (** $\mathrm{p}<0.002), 4 \mathrm{~h}$ after HI $(* * * \mathrm{p}=0.0001)$, and $24 \mathrm{~h}$ after HI $(* * * \mathrm{p}=0.0001)$. b hGPX-tg hippocampus compared to WT: naïve $(* \mathrm{p}=0.05), 30 \mathrm{~min}$ after $\mathrm{HI}(* \mathrm{p}=0.05), 4 \mathrm{~h}$ after HI $(* \mathrm{p}<0.05)$, and $24 \mathrm{~h}$ after HI $\left({ }^{*} \mathrm{p}<0.03\right)$. Mean OD ( \pm SEM) normalized to $\mathrm{P} 9$ naïve. $\mathbf{c}-\mathbf{f}$ Representative photomicrograph of immunostaining for GPx counterstained with cresyl violet in naïve GPx-tg and WT brain: naïve GPx-tg cortex (c) and hippocampus (d); naïve WT cortex (e) and hippocampus (f). Scale bar (shown in c) $=100 \mu \mathrm{m}$ for all. 

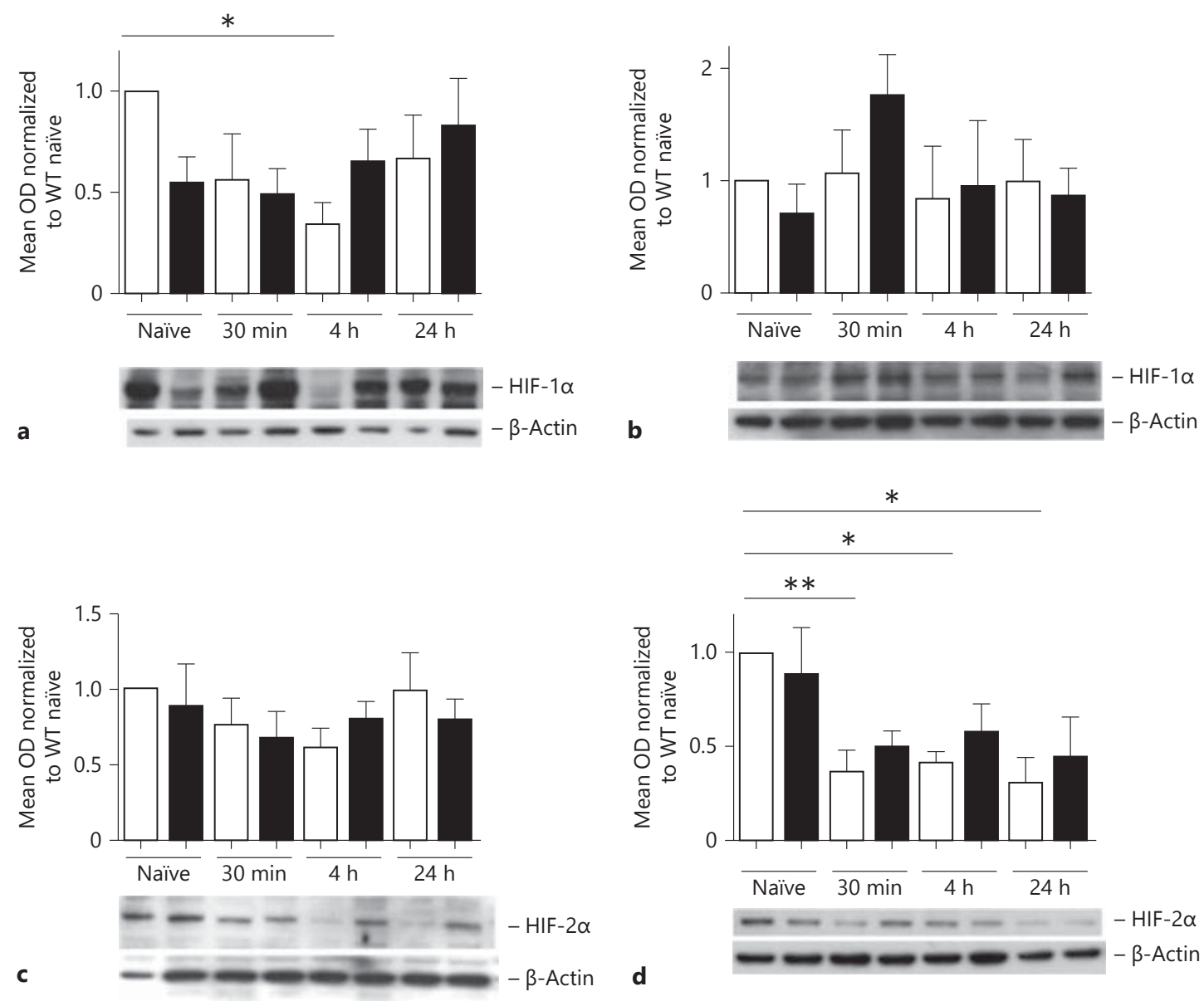

Fig. 2. HIF-1a (a, b) and HIF-2a (c, d) protein expression in the cortex and hippocampus. a HIF-1 $\alpha$ was decreased in the WT cortex $4 \mathrm{~h}$ after HI compared to WT naïve $\left({ }^{*} \mathrm{p}<0.04\right)$. b HIF-1a expression was not changed in the hippocampus. c HIF-2a expres-

activation in both the WT and hGPx-tg hippocampus at $4 \mathrm{~h}$ and in the cortex at $24 \mathrm{~h}$. The ERK1/2 pathway has been shown to be part of potentially protective mechanisms in neonatal HI [27], and ERK1/2 phosphorylation has been shown to peak prior to the peak expression of HIF-1 $\alpha$ in the developing rat brain after HI [21], which may indicate an alternate pathway for EPO expression.

While activation and stabilization of HIF- $1 \alpha$ is a wellestablished consequence of hypoxia, reports vary for HI. We recently showed increased HIF- $1 \alpha$ at $15 \mathrm{~min}$ and 4 and $24 \mathrm{~h}$ in mice after hypoxia but an increase only at $15 \mathrm{~min}$ (not at 4 or $24 \mathrm{~h}$ ) after HI [13]. However, ChavezValdez et al. [28] have shown increased HIF-1 $\alpha$ in mice $24 \mathrm{~h}$ after HI but not after $3 \mathrm{~h}$. In rats, HIF-1 $\alpha$ has been sion was not changed in the cortex. d HIF-2a decreased in the WT hippocampus after HI compared to WT naïve at $30 \min (* * \mathrm{p}<$ $0.006), 4 \mathrm{~h}(* \mathrm{p}<0.04)$ and $24 \mathrm{~h}(* \mathrm{p}<0.03)$.

shown to be upregulated, beginning at $4 \mathrm{~h}$ and peaking at $8 \mathrm{~h}$ after HI $[21,29]$.

A possible explanation for the paradoxical EPO upregulation in the hGPx-tg brain relative to WT is differing degrees of injury, differing cell death mechanisms (depending on time after $\mathrm{HI}$ ) and regional variation between the cortex and hippocampus. Indeed, in the cortex, spectrin 145/150 was increased in WT at both 4 and $24 \mathrm{~h}$ after HI relative to WT naïve, suggesting early and prolonged necrotic cell death in the WT cortex. Spectrin 120, on the other hand, increased only at $24 \mathrm{~h}$ in the WT cortex compared to both WT naïve and hGPx-tg after HI, indicating apoptotic mechanisms at this stage. In the hippocampus, there were no differences in spectrin $145 / 150$, indicating a low amount of necrosis in this region. Spectrin 120, 


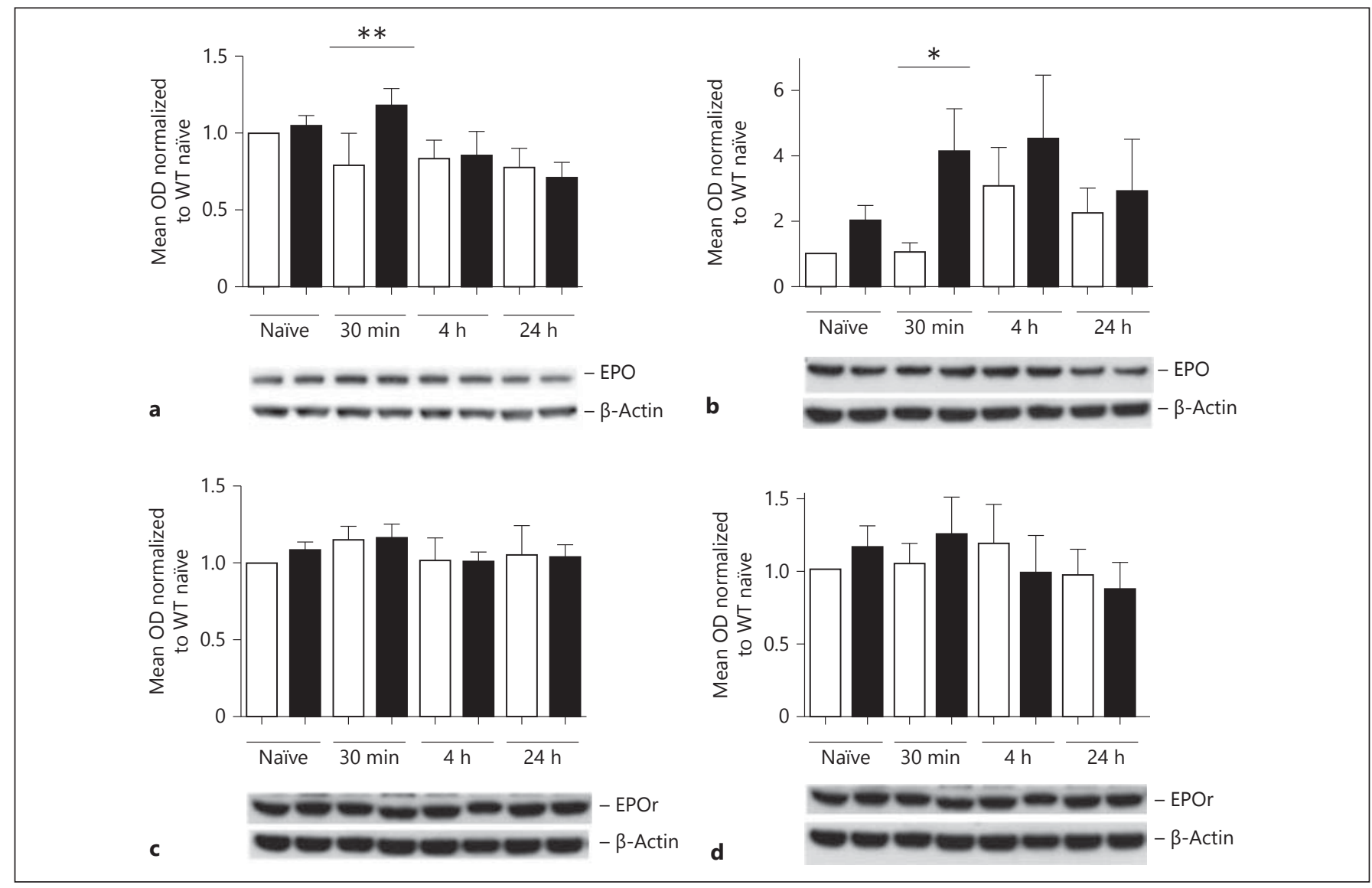

Fig. 3. $\operatorname{EPO}(\mathbf{a}, \mathbf{b})$ and EPOr (c, d) expression in the cortex and hippocampus. a EPO expression was higher in the hGPx-tg cortex 30 min after HI compared to the WT cortex $\left({ }^{* *} \mathrm{p}<0.008\right)$. b EPO expression was also higher in the hGPx-tg hippocampus $30 \mathrm{~min}$

after HI compared to the WT hippocampus (* $\mathrm{p}<0.04)$. EPOr, however, did not demonstrate any differences between GPx-tg and WT in the cortex (c) or hippocampus (d) for the naïve or any treatment group.

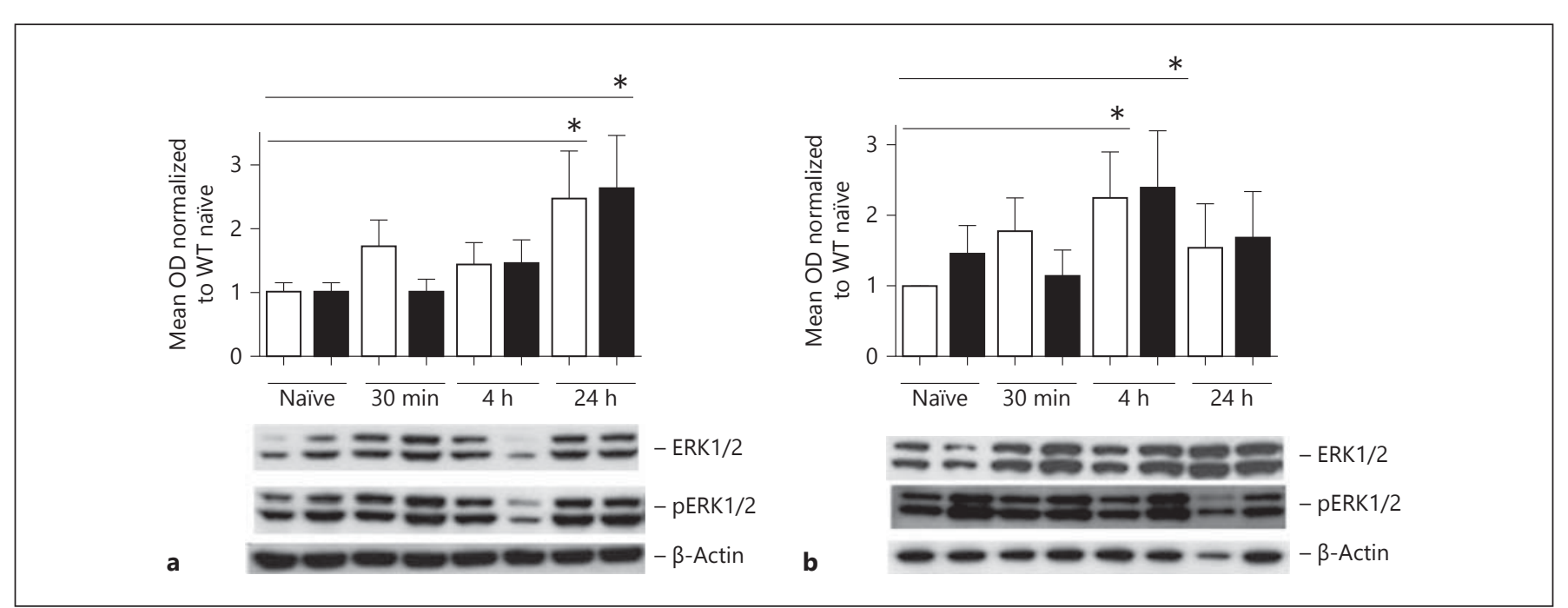

Fig. 4. ERK1/2 phosphorylation in the cortex and hippocampus. a Phospho-ERK1/2 is increased in the cortex of both WT $(* \mathrm{p}<$ $0.03)$ and hGPx-tg $(* \mathrm{p}<0.05) 24 \mathrm{~h}$ after HI compared to WT na-

GPx in Neonatal Hypoxia-Ischemia ive. $\mathbf{b}$ Phospho-ERK1/2 is increased in the hippocampus of both WT $(* \mathrm{p}=0.05)$ and hGPx-tg $(* \mathrm{p}<0.03) 4 \mathrm{~h}$ after HI compared to $\mathrm{WT}$ naïve. 


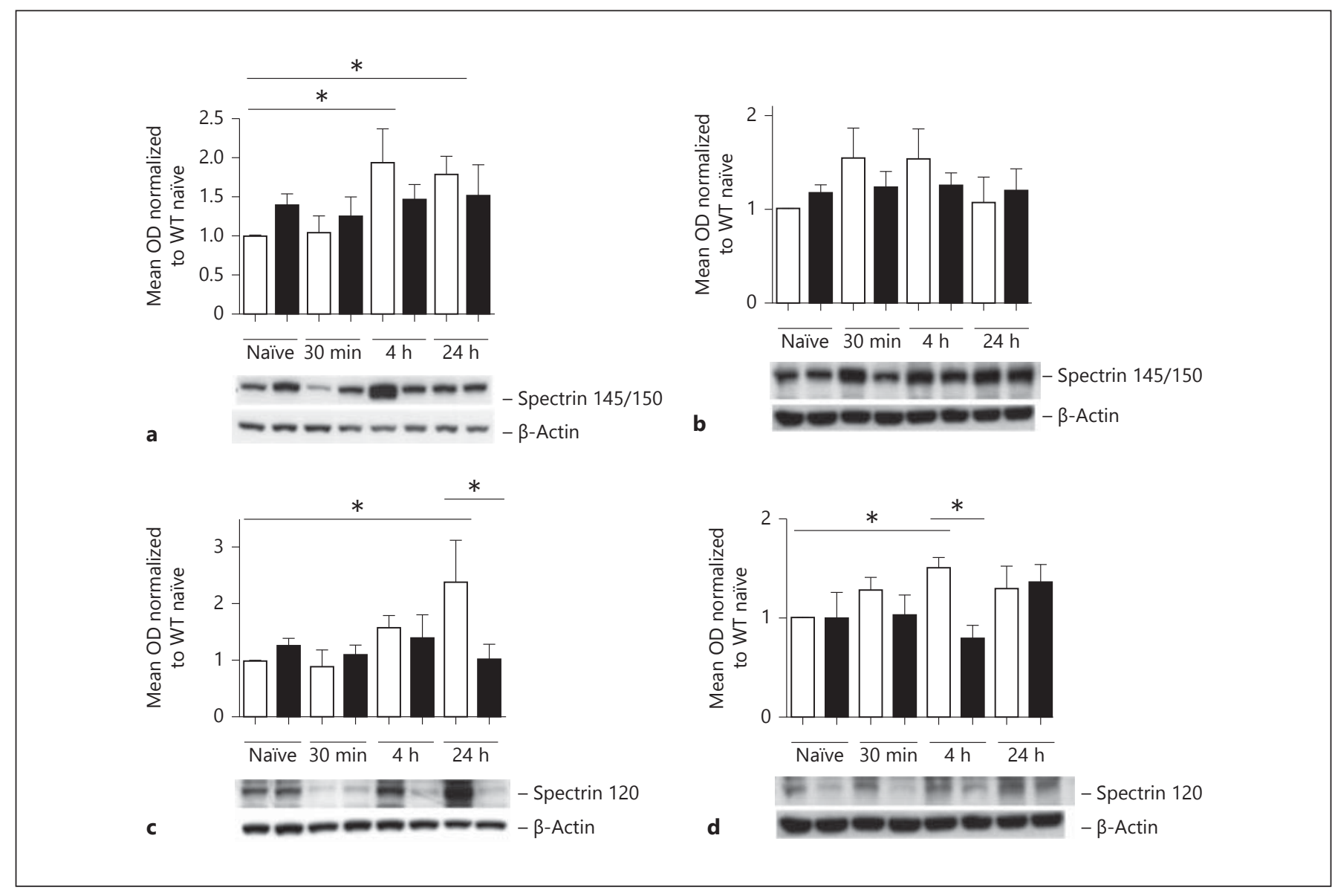

Fig. 5. Spectrin 145/150 and spectrin 120 indicate cell death mechanisms. a Spectrin 145/150 increased in the WT cortex $4 \mathrm{~h}\left({ }^{*} \mathrm{p}<\right.$ $0.04)$ and $24 \mathrm{~h}(* \mathrm{p}=0.05)$ after HI compared to WT naïve. There were no changes in spectrin 145/150 in the hGPx-tg cortex. b Spectrin $145 / 150$ increased in the hGPx-tg hippocampus 30 min after HI compared to WT 30 min after HI $(* \mathrm{p}<0.04)$. c Spectrin 120

however, increased at $4 \mathrm{~h}$ in the hippocampus. Thus, the WT brain experiences ongoing necrotic injury by $4 \mathrm{~h}$ in the cortex, which is exacerbated by apoptosis by $24 \mathrm{~h}$. Cell death in the WT hippocampus, however, is largely - if not entirely - apoptotic, beginning by $4 \mathrm{~h}$. These results may have relevance to the observation that the hippocampus is particularly vulnerable to HI injury in the mouse, and hippocampal neurons are more susceptible to oxidative stress in vitro [30]. The hippocampal white matter may also be more susceptible to cell death processes than cortical white matter. HIF- $2 \alpha$, thought to be astrocyte specific, declined in the WT hippocampus at all time points after $\mathrm{HI}$ but was not significantly altered in the WT cortex. As astrocytes are important for the clearance of $\mathrm{H}_{2} \mathrm{O}_{2}$, this may also be a reflection of increased injury in the $\mathrm{WT}$, increased in WT cortex $24 \mathrm{~h}$ after HI compared to hGPx-tg $24 \mathrm{~h}$ after $\mathrm{HI}\left({ }^{*} \mathrm{p}=0.05\right)$, as well as compared to WT naïve $(* \mathrm{p}=0.05)$. d In the hippocampus, spectrin 120 was higher in WT $4 \mathrm{~h}$ after HI compared to hGPx-tg $\left({ }^{*} \mathrm{p}=0.03\right)$, as well as to WT naïve $\left({ }^{*} \mathrm{p}<\right.$ 0.05).

particularly the hippocampus. The hGPx-tg brain displayed neither spectrin 145/150 nor spectrin 120 upregulation, reflecting the resistance to $\mathrm{HI}$ injury we have previously seen in these mice [4].

GPx is a relatively neglected enzyme in the study of oxidative stress, despite its critical role in the protection of the brain against oxidative stress and inflammation in a number of conditions such as stroke, neurodegenerative disorders, traumatic brain injury, and HI [31]. Previous work by our group and others has also suggested that HIF- $1 \alpha$ is involved in the mechanisms of protection from HI $[12,29,32,33]$. Indeed, like the hGPx-tg mice, hypoxia preconditioning protection is lost in HIF-1a knockout mice after neonatal HI [13]. When neonatal mice that have both GPx overexpression and HIF-1 $\alpha$ reduction - 
hybrid offspring of the hGPx-tg and HIF-1 $1 \alpha$ knockout the outcome is worse injury than WT littermates, indicating that the protective effect of increased GPx is lost in the setting of HIF- 1 a knockdown, implying a role for HIF- 1 a independent of the antioxidative mechanisms of GPx in the neonatal brain [unpubl. data].

It has been suggested that an antioxidant state with reduced levels of $\mathrm{H}_{2} \mathrm{O}_{2}$ limits the activation of the HIF pathway, whereas a prooxidant state allowing elevated $\mathrm{H}_{2} \mathrm{O}_{2}$ levels promotes it [34]. In fact, exogenous $\mathrm{H}_{2} \mathrm{O}_{2}$ has been shown to upregulate HIF-1a and provide preconditioning protection to neurons in vitro [35]. Perhaps the activation of HIF- $1 \alpha$ and its target genes is necessary for protection in neonatal HI. In this case, the lack of any increase in HIF-1 $1 \alpha$ in the hGPx-tg brain in response to $\mathrm{HI}$ seen here is not surprising given the presumably low amounts of $\mathrm{H}_{2} \mathrm{O}_{2}$ present. In fact, it may be that ERK activation is more important in the setting of low $\mathrm{H}_{2} \mathrm{O}_{2}$ and is affected by $\mathrm{GPx} 1$ overexpression. We have previously shown that GPx1 overexpression prevents both the global and nuclear increase in activated
ERK at $0.5 \mathrm{~h}$ after hypoxic preconditioning (HPC) and causes a significant decrease in phospho-ERK/ERK levels at $24 \mathrm{~h}$ after HPC, thus explaining the lack of HPC in these GPx brains [20].

Further confirmation of the importance of GPx in protection from neonatal $\mathrm{HI}$ are seen in results from our laboratory with GPx knockout mice, indicating that $\mathrm{HI}$ injury is the same as WT in these mice after HI [unpubl. data]. We have yet to determine the status of HIF in these animals.

In summary, HIF-1a may have a more complex role in neonatal HI than previously believed. The antioxidant status of the brain may influence some of the mechanisms regulated by HIF- $\alpha$. A better understanding of these mechanisms may lead to improved therapy for human neonates with $\mathrm{HI}$ encephalopathy.

\section{Acknowledgment}

This work was funded by NIH grant NS33997.

\section{References}

1 McQuillen PS, Ferriero DM: Selective vulnerability in the developing central nervous system. Pediatr Neurol 2004;30:227-235.

2 Lafemina MJ, Sheldon RA, Ferriero DM: Acute hypoxia-ischemia results in hydrogen peroxide accumulation in neonatal but not adult mouse brain. Pediatr Res 2006;59:680 683.

3 Khan JY, Black SM: Developmental changes in murine brain antioxidant enzymes. Pediatr Res 2003;54:77-82.

4 Sheldon RA, Jiang X, Francisco C, Christen S, Vexler ZS, Tauber MG, Ferriero DM: Manipulation of antioxidant pathways in neonatal murine brain. Pediatr Res 2004;56:656-662.

5 McLean CW, Mirochnitchenko O, Claus CP, Noble-Haeusslein LJ, Ferriero DM: Overexpression of glutathione peroxidase protects immature murine neurons from oxidative stress. Dev Neurosci 2005;27:169-175.

6 Crack PJ, Taylor JM, Flentjar NJ, de Haan J, Hertzog P, Iannello, RC, Kola I: Increased infarct size and exacerbated apoptosis in the glutathione peroxidase-1 (Gpx-1) knockout mouse brain in response to ischemia/reperfusion injury. J Neurochem 2001;78:13891399.

7 Sheldon RA, Aminoff A, Lee CL, Christen S, Ferriero DM: Hypoxic preconditioning reverses protection after neonatal hypoxia-ischemia in glutathione peroxidase transgenic murine brain. Pediatr Res 2007;61:666-670.

8 Gidday JM, Fitzgibbons JC, Shah AR, Park TS: Neuroprotection from ischemic brain injury by hypoxic preconditioning in the neonatal rat. Neurosci Lett 1994;168:221224.

9 Bergeron M, Yu AY, Solway KE, Semenza GL, Sharp, FR: Induction of hypoxia-inducible factor-1 (HIF-1) and its target genes following focal ischaemia in rat brain. Eur J Neurosci 1999;11:4159-4170.

10 Feng Y, Rhodes PG, Bhatt AJ: Hypoxic preconditioning provides neuroprotection and increases vascular endothelial growth factor A, preserves the phosphorylation of AktSer-473 and diminishes the increase in caspase- 3 activity in neonatal rat hypoxic-ischemic model. Brain Res 2010;1325:1-9.

$11 \mathrm{Mu}$ D, Jiang X, Sheldon RA, Fox CK, Hamrick SE, Vexler ZS, Ferriero, DM: Regulation of hypoxia-inducible factor $1 \alpha$ and induction of vascular endothelial growth factor in a rat neonatal stroke model. Neurobiol Dis 2003; 14:524-534.

12 Sheldon RA, Osredkar D, Lee CL, Jiang X, $\mathrm{Mu}$ D, Ferriero DM: HIF-1a-deficient mice have increased brain injury after neonatal hypoxia-ischemia. Dev Neurosci 2009;31: 452-458.

13 Sheldon RA, Lee CL, Jiang X, Knox RN, Ferriero DM: Hypoxic preconditioning protection is eliminated in HIF-1a knockout mice subjected to neonatal hypoxia-ischemia. Pediatr Res 2014;76:46-53.

14 Jantzie LL, Corbett CJ, Firl DJ, Robinson S: Postnatal erythropoietin mitigates impaired cerebral cortical development following sub- plate loss from prenatal hypoxia-ischemia. Cereb Cortex 2014, Epub ahead of print.

15 Traudt CM, McPherson RJ, Bauer LA, Richards TL, Burbacher TM, McAdams RM, Juul SE: Concurrent erythropoietin and hypothermia treatment improve outcomes in a term nonhuman primate model of perinatal asphyxia. Dev Neurosci 2013;35:491-503.

16 Gonzalez FF, Ferriero DM: Therapeutics for neonatal brain injury. Pharmacol Ther 2008 ; 120:43-53.

17 Kumral A, Gonenc S, Acikgoz O, Sonmez A, Genc K, Yilmaz O, Gokmen N, Duman N, Ozkan H: Erythropoietin increases glutathione peroxidase enzyme activity and decreases lipid peroxidation levels in hypoxic-ischemic brain injury in neonatal rats. Biol Neonate 2005;87: $15-18$.

18 Fan X, Heijnen CJ, van der Kooij M, Groenendaal F, van Bel F: Beneficial effect of erythropoietin on sensorimotor function and white matter after hypoxia-ischemia in neonatal mice. Pediatr Res 2011;69:56-61.

19 Fang AY, Gonzalez FF, Sheldon RA, Ferriero DM: Effects of combination therapy using hypothermia and erythropoietin in a rat model of neonatal hypoxia-ischemia. Pediatr Res 2013;73:12-17.

20 Autheman D, Sheldon RA, Chaudhuri N, von Arx S, Siegenthaler C, Ferriero DM, Christen S: Glutathione peroxidase overexpression causes aberrant ERK activation in neonatal mouse cortex after hypoxic preconditioning. Pediatr Res 2012;72:568-575. 
21 Li L, Xiong Y, Qu Y, Mao M, Mu W, Wang H, $\mathrm{Mu} \mathrm{D}$ : The requirement of extracellular signal-related protein kinase pathway in the activation of hypoxia inducible factor 1 alpha in the developing rat brain after hypoxia-ischemia. Acta Neuropathol 2008;115:297-303.

22 Chavez JC, Baranova O, Lin J, Pichiule P: The transcriptional activator hypoxia inducible factor 2 (HIF-2/EPAS-1) regulates the oxygen-dependent expression of erythropoietin in cortical astrocytes. J Neurosci 2006;26: 9471-9481.

23 Mirault ME, Tremblay A, Furling D, Trepanier G, Dugre F, Puymirat J, Pothier F: Transgenic glutathione peroxidase mouse models for neuroprotection studies. Ann NY Acad Sci 1994;738:104-115.

24 Rice JE, Vannucci RC, Brierley JB: The influence of immaturity on hypoxic-ischemic brain damage in the rat. Ann Neurol 1981;9: 131-141.

25 Ditelberg JS, Sheldon RA, Epstein CJ, Ferriero DM: Brain injury after perinatal hypoxiaischemia is exacerbated in copper/zinc superoxide dismutase transgenic mice. Pediatr Res 1996;39:204-208.
26 Zhu C, Wang X, Xu F, Bahr BA, Shibata M, Uchiyama Y, Hagberg H, Blomgren K: The influence of age on apoptotic and other mechanisms of cell death after cerebral hypoxiaischemia. Cell Death Differ 2005;12:162-176.

27 Han BH, Holtzman DM: BDNF protects the neonatal brain from hypoxic-ischemic injury in vivo via the ERK pathway. J Neurosci 2000; 20:5775-5781.

28 Chavez-Valdez R, Martin LJ, Flock DL, Northington FJ: Necrostatin-1 attenuates mitochondrial dysfunction in neurons and astrocytes following neonatal hypoxia-ischemia. Neuroscience 2012;219:192-203.

29 Chen H, Xiong T, Qu Z, Zhao F, Ferriero DM, $\mathrm{Mu} \mathrm{D}$ : mTOR activates hypoxia-inducible factor-1 $\alpha$ and inhibits neuronal apoptosis in the developing rat brain during the early phase after hypoxia-ischemia. Neurosci Lett 2012;507:118-123.

30 Jiang X, Mu D, Manabat C, Koshy AA, Christen S, Tauber MG, Vexler ZS, Ferriero DM: Differential vulnerability of immature murine neurons to oxygen-glucose deprivation. Exp Neurol 2004;190:224-232.
31 Chen W, Jadhav V, Tang J, Zhang JH: HIF-1a inhibition ameliorates neonatal brain injury in a rat pup hypoxic-ischemic model. Neurobiol Dis 2008;31:433-441.

32 Li L, Qu Y, Li J, Xiong Y, Mao M, Mu D: Relationship between HIF-1a expression and neuronal apoptosis in neonatal rats with hypoxia-ischemia brain injury. Brain Res 2007; 1180:133-139.

33 Fan X, Heijnen CJ, van der Kooij MA, Groenendaal F, van Bel F: The role and regulation of hypoxia-inducible factor-1 $\alpha$ expression in brain development and neonatal hypoxic-ischemic brain injury. Brain Res Rev 2009;62:99-108.

34 BelAiba RS, Djordjevic T, Bonello S, Flugel D, Hess J, Kietzmann T, Gorlach A: Redox-sensitive regulation of the HIF pathway under non-hypoxic conditions in pulmonary artery smooth muscle cells. Biol Chem 2004;385: 249-257.

35 Chang YC, Huang CC: Perinatal brain injury and regulation of transcription. Curr Opin Neurol 2006; 19:141-147. 